\title{
A FIXED POINT THEOREM FOR MAPPINGS WITH A CONTRACTIVE ITERATE
}

\author{
V. M. SEHGAL
}

1. Let $(X, d)$ be a metric space and $f: X \rightarrow X$ a mapping. If $f$ satisfies the condition

$$
d(f(x), f(y)) \leqq k d(x, y)
$$

for all $x, y \in X$ and for some $k<1$, then $f$ is called a contraction.

A well-known theorem of Banach [1] states that for $X$ complete, each contraction mapping $f$ has a unique fixed point $u$, and the successive approximations $\left\{f^{n}\left(x_{0}\right)\right\}$ converge to $u$ for each $x_{0} \in X$. In this paper, we investigate mappings which are not necessarily contractions and prove the following result.

Theorem. Let $(X, d)$ be a complete metric space, and $f: X \rightarrow X$ a continuous mapping satisfying the condition: there exists a $k<1$ such that for each $x \in X$, there is a positive integer $n(x)$ such that for all $y \in X$

$$
d\left(f^{n(x)}(y), f^{n(x)}(x)\right) \leqq k d(y, x) .
$$

Then $f$ has a unique fixed point $u$ and $f^{n}\left(x_{0}\right) \rightarrow u$ for each $x_{0} \in X$.

Lemma. If $f: X \rightarrow X$ be any mapping satisfying the condition of the above theorem then for each $x \in X, r(x)=\sup _{n} d\left(f^{n}(x), x\right)$ is finite.

Proof. Let $x \in X$ and let

$$
l(x)=\max \left\{d\left(f^{k}(x), x\right): k=1,2, \cdots, n(x)\right\} .
$$

If $n$ is a positive integer, there exists an integer $s \geqq 0$ such that $s \cdot n(x)$ $<n \leqq(s+1) \cdot n(x)$, and

$$
\begin{aligned}
d\left(f^{n}(x), x\right) & \leqq d\left(f^{n(x)} \cdot f^{n-n(x)}(x), f^{n(x)}(x)\right)+d\left(f^{n(x)}(x), x\right) \\
& \leqq k d\left(f^{n-n(x)}(x), x\right)+l(x) \\
& \leqq l(x)+k l(x)+k^{2} l(x)+\cdots+k^{8} l(x) \\
& \leqq l(x) /(1-k) \quad \text { for all } n \geqq 0 .
\end{aligned}
$$

Hence $r(x)=\sup _{n} d\left(f^{n}(x), x\right)$ is finite.

PRoOF of THE THEOREM. Let $x_{0} \in X$ be arbitrary. Let $m_{0}=n\left(x_{0}\right)$, $x_{1}=f^{m_{0}}\left(x_{0}\right)$ and inductively $m_{i}=n\left(x_{i}\right), x_{i+1}=f^{m_{i}}\left(x_{i}\right)$. We show that

Received by the editors February 12, 1969. 
the sequence $\left\{x_{n}\right\}$ is a convergent sequence. By routine calculation we have

$$
\begin{aligned}
d\left(x_{n+1}, x_{n}\right) & =d\left(f^{m_{n-1}} \cdot f^{m_{n}}\left(x_{n-1}\right), f^{m_{n-1}}\left(x_{n-1}\right)\right) \leqq k d\left(f^{m_{n}}\left(x_{n-1}\right), x_{n-1}\right) \leqq \cdots \\
& \leqq k^{n} d\left(f^{m_{n}}\left(x_{0}\right), x_{0}\right) .
\end{aligned}
$$

Therefore, it follows by lemma that $d\left(x_{n+1}, x_{n}\right) \leqq k^{n} r\left(x_{0}\right)$. Thus, for $m>n$,

$$
d\left(x_{m}, x_{n}\right) \leqq \sum_{i=n}^{m-1} d\left(x_{i+1}, x_{i}\right) \leqq \frac{k^{n}}{1-k} r\left(x_{0}\right) \rightarrow 0 \quad \text { as } n \rightarrow \infty .
$$

The sequence $\left\{x_{n}\right\}$ is therefore Cauchy. Let $x_{n} \rightarrow u \in X$.

If $f(u) \neq u$, then, there exists a pair of disjoint closed neighborhoods $U$ and $V$ such that $u \in U, f(u) \in V$ and

$$
\rho=\operatorname{Inf}\{d(x, y): x \in U, y \in V\}>0 .
$$

Since $f$ is continuous, $x_{n} \in U$ and $f\left(x_{n}\right) \in V$ for all $n$ sufficiently large. However,

$$
\begin{aligned}
d\left(f\left(x_{n}\right), x_{n}\right) & =d\left(f^{m_{n-1}} \cdot f\left(x_{n-1}\right), f^{m_{n-1}}\left(x_{n-1}\right)\right) \leqq k d\left(f\left(x_{n-1}\right), x_{n-1}\right) \leqq \cdots \\
& <k^{n} d\left(f\left(x_{0}\right), x_{0}\right) \rightarrow 0
\end{aligned}
$$

as $n \rightarrow \infty$, contradicting (3). Thus $f(u)=u$.

The uniqueness of the fixed point follows immediately from (2). To show that $f^{n}\left(x_{0}\right) \rightarrow u$, set

$$
\rho_{*}=\max \left\{d\left(f^{m}\left(x_{0}\right), u\right): m=0,1,2 \cdots,(n(u)-1)\right\} .
$$

If $n$ is a sufficiently large integer, then $n=r \cdot n(u)+q, 0 \leqq q<n(u)$, $r>0$, and

$$
\begin{aligned}
d\left(f^{n}\left(x_{0}\right), u\right) & =d\left(f^{r \cdot n(u)+q}\left(x_{0}\right), f^{n(u)}(u)\right) \leqq k d\left(f^{(r-1) \cdot n(u)+q}\left(x_{0}\right), u\right) \leqq \cdots \\
& \leqq k^{r} d\left(f^{q}\left(x_{0}\right), u\right) \leqq k^{r} \rho_{*} .
\end{aligned}
$$

Since $n \rightarrow \infty$ implies $r \rightarrow \infty$, we have $d\left(f^{n}\left(x_{0}\right), u\right) \rightarrow 0$ as $n \rightarrow \infty$. This establishes the theorem.

2. In this section we give an example of a continuous function $f$ which satisfies condition (2), but is not a contraction. The author is thankful to the referee for showing that no iterate of $f$ is a contraction. Bryant [2] considers a function $f$ (not necessarily continuous) on a complete metric space $X$ in to itself for which there exists a $k, 0 \leqq k<1$, and a positive integer $n$, such that $d\left(f^{n}(x), f^{n}(y)\right) \leqq k d(x, y)$ for all $x, y \in X$. That Bryant's condition is stronger than condition (2) is shown below. The author is grateful to Professor David R. Anderson for his help in the following example. 
ExAmple. Let $X$ be the closed unit interval $[0,1]$ with the usual metric. Write

$$
X=\bigcup_{n=1}^{\infty}\left[\frac{1}{2^{n}}, \frac{1}{2^{n-1}}\right] \cup\{0\},
$$

and let $f: X \rightarrow X$ be defined as follows.

For each $n=1,2 \cdots$, let

$$
f:\left[\frac{1}{2^{n}}, \frac{1}{2^{n-1}}\right] \rightarrow\left[\frac{1}{2^{n+1}}, \frac{1}{2^{n}}\right]
$$

be defined by

$$
\begin{aligned}
f(x) & =\frac{n+2}{n+3}\left(x-\frac{1}{2^{n-1}}\right)+\frac{1}{2^{n}}, & & \text { if } x \in\left[\frac{3 n+5}{2^{n+1}(n+2)}, \frac{1}{2^{n-1}}\right] \\
& =\frac{1}{2^{n+1}} & & \text { if } x \in\left[\frac{1}{2^{n}}, \frac{3 n+5}{2^{n+1}(n+2)}\right]
\end{aligned}
$$

and let $f(0)=0$.

It is obvious that $f$ is a nondecreasing, continuous function on $[0,1]$ with 0 as the only fixed point, and that $f$ is not a contraction. If $x \in\left[1 / 2^{n}, 1 / 2^{n-1}\right]$ and $y \in X$, then by a routine examination of cases $y \in\left[1 / 2^{m}, 1 / 2^{m-1}\right]$ for $m \geqq n$ and $m \leqq n$, it is easy to verify that $f$ satisfies

$$
|f(x)-f(y)| \leqq \frac{n+3}{n+4}|x-y| \quad \text { for all } y \in X .
$$

Therefore, if we choose $k=1 / 2$ in (2), then for each $x \in\left[1 / 2^{n}, 1 / 2^{n-1}\right]$, $n(x)$ may be taken as $n+3$, whereas $n(0)$ may be taken as any integer greater than one.

To show that the condition in [2] is stronger than (2), let $0 \leqq k<1$, and $N$ (a natural number) be given; it will be shown that there exists $x$ and $y$ such that $\left|f^{N}(x)-f^{N}(y)\right|>k|x-y|$. Choose and fix $n>(N k / 1-k))-2$. Since $f^{i}$ is uniformly continuous on $[0,1]$ for $i=1,2, \cdots, N$, there is some $\delta>0$ such that

$$
|x-y|<\delta \Rightarrow\left|f^{i}(x)-f^{i}(y)\right|<\frac{n+N+3}{(n+N+2) 2^{n+N+1}}
$$

for $i=1,2, \cdots, N$. Setting $x=1 / 2^{n-1}$ and $y$ any member of $\left[1 / 2^{n}, 1 / 2^{n-1}\right]$ such that $0<|x-y|<\delta$, it can be shown that $f^{i}(x)$ and $f^{i}(y)$ are both members of 


$$
\left[\frac{3(n+i)+5}{2^{n+i+1}(n+i+2)}, \frac{1}{2^{n+i-1}}\right]
$$

for $i=1,2, \cdots, N$. Thus

$$
\begin{aligned}
\mid f(x) & -f(y)\left|=\frac{n+2}{n+3}\right| x-y \mid \\
\left|f^{2}(x)-f^{2}(y)\right| & =\frac{n+2}{n+4}|x-y|, \cdots,\left|f^{N}(x)-f^{N}(y)\right| \\
& =\frac{n+2}{n+2+N}|x-y|>k|x-y| .
\end{aligned}
$$

The author acknowledges the help of Professor A. T. BharuchaReid in the preparation of this paper.

\section{REFERENCES}

1. S. Banach, Sur les opérations dan les ensembles abstraits et leurs applications aux integrales, Fund. Math. 3 (1922), 133-181.

2. V. W. Bryant, $A$ remark on a fixed point theorem for iterated mappings, Amer. Math. Monthly 75 (1968), 399-400.

UNIVERSITY OF WYOMING 